\title{
The Integrated Design of Leadership Development
}

\author{
Liangtie Dai, Jia Li \\ Management School, Jinan University, Guangzhou, China \\ Email: 973360724@qq.com
}

Received 25 July 2016; accepted 23 August 2016; published 26 August 2016

Copyright (C) 2016 by authors and Scientific Research Publishing Inc.

This work is licensed under the Creative Commons Attribution International License (CC BY). http://creativecommons.org/licenses/by/4.0/

cc) (7) Open Access

\begin{abstract}
Leadership development is considered to be the way to promote organizational change and deal with environmental challenges, and integrated design can effectively improve leadership development. This paper first gives a brief introduction to the integrated design of leadership development, which contains competency modeling, talent assessment and training based on the action learning. Then the author introduces the three parts of integrated design in detail, including their concepts, methods and process. The studying of the integrated design has theoretical significance and practical significance to the enterprise.
\end{abstract}

\section{Keywords}

Leadership Development, The Integrated Design of Leadership Development, Competency Modeling, Talent Assessment, Action Learning

\section{Introduction}

Leadership refers to the ability of inspiring and guiding others to establish and implement common vision. Along with the development of economic globalization and cultural diversity, leadership has increasingly become an important source of organization competitive advantage, and leadership development is becoming an important subject in front of the researchers. Research shows that $91 \%$ of enterprises believe that leadership development is very important or priority, and $84 \%$ of enterprises have carried out or are launching a leadership development program. At present, the integrated design of leadership development is accepted by all kinds of organizations. This method can effectively solve the following problems in the process of leadership development: what kind of leadership enterprises really need, what kind of standard leadership development should achieve, identifying the current level of employee, the effectiveness of the training method and so on. It can not only improve the effectiveness of the leadership development, but also contribute to the improvement of enter- 
prise recruitment, training, talent team construction.

\section{Theoretical Basis}

On leadership development, theoretical research first achieved a significant transformation. Experts thought that leadership was inherent before, but now they believe that leadership can be cultivated [1]. Based on the point of leadership behavior school, we can embed effective behavior patterns into individuals by designing some training programs, which means that the leadership can be developed. Those leadership behaviors closely related to the performance, was placed on the leadership competency model. We can improve the leadership through effective leadership training.

Leadership model refers to the best behavior and leadership with the requirements of organization, industry and environment, which is essential to support the organization to achieve the established strategic objectives, and promote organization development. Leadership model is integrated of leader's competencies, including the quality, ability, attitude and behavior of leaders. Researchers put forward a variety of common leadership model, for example, the Chinese academy of sciences constructed the five leadership model based on the analysis of leadership process, including predictive power, charisma and influence, determination and control. From development object dimension, leadership development includes not only the development of individual leadership, also includes the development of individual connection and the growth of the collective capacity. Studies have shown that the leadership model is closely connected with leadership development. Ren Changjiang suggested leadership development could strengthen the identified leadership competency model continually [2]; XinWen thought that leadership model is the foundation of enterprises leadership project implementation [3]. Maowei Wen pointed out that almost all leadership development programs have a clear leadership competency model based on the behavior characteristics, which was the core and focus of the program [4].

\section{The Process of Integrated Design}

Integrated design is the mainstream of the current leadership development solutions, including building the standard, finding the gap, training. Typical integrated design as shown in Figure 1.

First, build leadership model through various research. Corporate strategy, business, and development plan put forward new requirements to the leadership, leadership model should include business skills, leadership skills and personal characteristics. Second, develop customized assessment tools, carry out the talent assessment to find out the gap between current level and the target ability. Third, make a plan based on the gap and conduct the training by action learning. After the training, test the result of training using the leadership model again, assess the change of behavior and ability of participants. Leadership development is a gradual and dynamic system, leadership model should change along with the development of the enterprise.

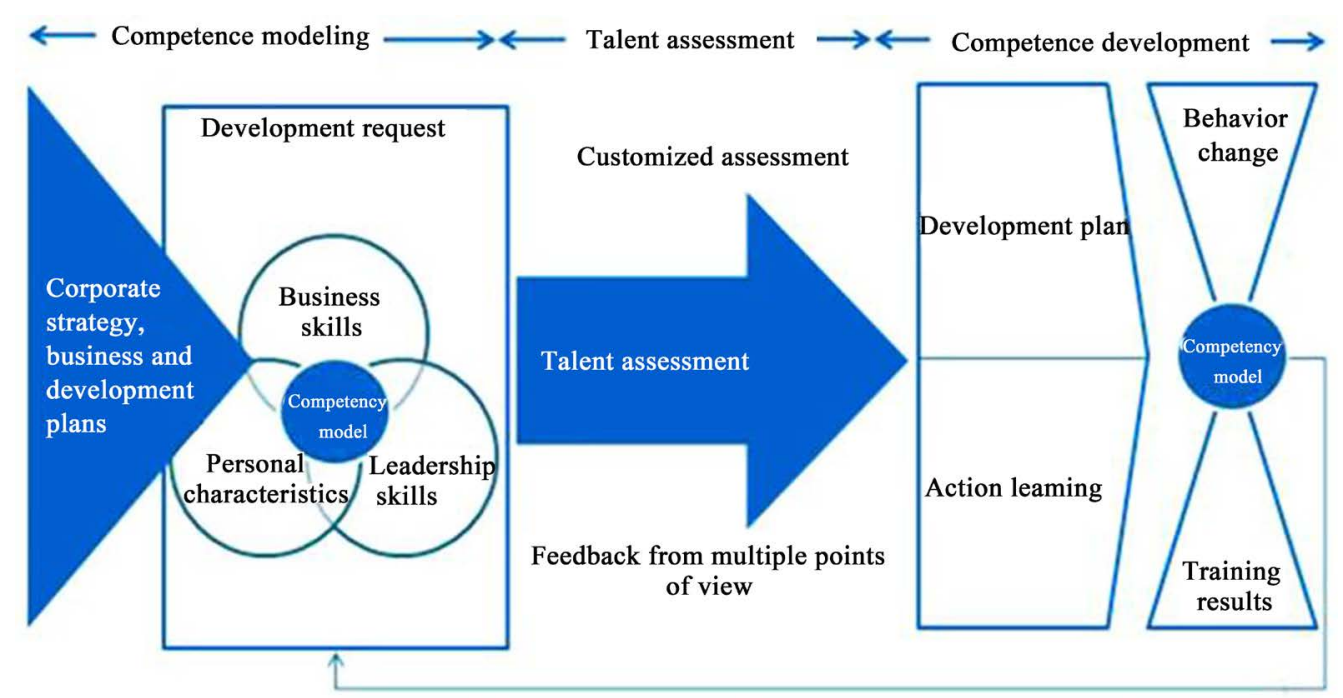

Figure 1.The integrated design of leadership development. 


\subsection{Competency Modeling}

\subsubsection{The Characteristics of the Competency Model}

McClelland pointed out that competency refers to personal characteristics which can distinguish job performance in specific position and organizational environment. Competency has the following three important features:

- Close relationship with job performance, even can predict the employee's job performance in future;

- Associated with work situation, which is dynamic;

- Distinguish between good performance and ordinary performance.

So not all of the knowledge, skills and personal characteristics are considered as competency, meeting the three important characteristics is essential. Competency model plays an important role in enterprise recruitment, training, performance management and employee career planning.

\subsubsection{The Method of Building Competency Model}

It is a very important problem to ensure the scientific city and effectiveness of the competency modeling. Scholars have proposed many methods, such as focus interviews, group multi-level level investigation method, expert investigation, expert meeting, etc. But scholars agree that behavioral event interview method is very effective on competency elements reveal. Spencer improved the competency model building methods based on McClelland:

- Determine effective performance standards. Hard indicator such as sales, profit; soft indicator such as the evaluation of the superior and colleague;

- Select the samples, distinguish between the excellent performance and ordinary performance;

- Collect data by behavioral event interview, 360-degree evaluation and field observation, theme analysis and expert system database;

- Extract competency indicators by information encoding, then build the competency model;

- Verify the competency model;

- Widely used in personnel selection, performance evaluation, training, compensation management, and other human resources management practice.

\subsection{Talent Assessment}

Enterprise talent assessment lays a solid foundation for subsequent training, which has double meaning for organizations and individuals. From the organizational level, the evaluation result can help the company fully grasp the ability of the team, which can contribute to make a scientific and targeted training plan. From a personal level, it makes participants realize their own current ability objectively, reflect on their own ability gap and have a strong desire to improve themselves. Besides, it makes participants pay attention to select and develop subordinates in order to enhance the overall ability of the team.

\subsubsection{The Program of Talent Assessment}

Talent assessment based on the competency model can be divided into the following steps:

- Build competency models of target positions;

- Select evaluation method. It depends on three key elements: competent characteristic model, the return on investment, and the acceptable degree of candidates;

- Train assessors and make sure they can grasp evaluation methods and skills;

- Implement the assessment;

- Analysis assessment result. Define the present ability of team and individual, find out the gap and make the training objectives.

\subsubsection{Talent Assessment Technology}

There are many talent assessment tools can be used. Generally speaking, we divide them into the following three categories:

1) The paper and pencil psychological test method.

The commonly used tests include Ability test, personality test and motivation test. Ability test contain wechsler intelligence test, raven reasoning test, etc. Personality test includes five test, 16PF, CPI, etc. Motivation test include TAT test, sentence completion test.

2) The behavioral event interview technique. 
It is the most effective and original way to study competence characteristics. Candidates describe how they handle the "very good" and "very poor" incidents, assessors determine whether they have required ability in a particular position through qualitative and quantitative analysis of the key events. This method is more convenient and practical than the observation method. Compared with the method of observation, the behavioral event interview has the following advantages: first, accurately reveal how to handle a specific or difficult task of the excellent worker; Second, provide materials for organizational assessment, training, career planning, provide specific description for effective or ineffective work behavior, which can provides experience for other people's behavior in the future; Third, the interview produces a series of vivid stories and cases, which helps effectively understand, experience and draw lessons from others.

3) The scenario simulation method.

This method is to observe the action in simulative work situation to determine specific competencies needed for the job. Common methods for scenario simulation test include no leadership group discussion, basket, role playing, management games, etc. Scenario simulation technology realizes the dynamic test, and you can test out competence characteristics which cannot be tested out in intelligence test.

\subsection{Training Based on the Action Learning}

Compared with traditional personnel training methods, action learning has unique advantages, widely accepted throughout the world.

\subsubsection{Traditional Methods VS Action Learning}

British RegVince formally put forward the theory and method of action learning in the paper "develop efficient managers" in 1971. Professor Vince says: action learning is a kind of development mean, and participants seriously involve in the real, complicated and pressing problems, pay a mental, emotional or physical input, and get the desired behavior changes [5]. In 1999, Hicks and Peterson put forward leadership development channel model including self-awareness, learning motivation, skill development, practical development, internal migration [6]. They believe that each element in the development channel represents a key element, represents the core control points, determines actual level and effect of all leadership training or development. Thus, in this sense, all sorts of popular leadership development method can use "leadership development channel model" to analyze and evaluate. Leadership development program only teaching classroom training content from the trainer to the trainees without application practice is less effective. Based on this, compare, analyze and evaluate a variety of leadership development method such as developmental evaluation aiming at IDP based on test, tutor system developmental tasks, coach coaching and action learning, and enumerates their estimators of the extent of meeting the demand of each element in the channel. As shown in Table 1:

\section{Table 1. Validity estimators of typical leadership development method [6].}

\begin{tabular}{|c|c|c|c|c|c|}
\hline Program type & Self-awareness & Learning motivation & Skill development & Practical development & Internal migration \\
\hline $\begin{array}{l}\text { Developmental evaluation } \\
\text { aiming at IDP based on test }\end{array}$ & $\mathrm{S}$ & M & $\mathrm{W}$ & W & $\mathrm{W}$ \\
\hline Tutor system & $\mathrm{M}$ & $\mathrm{S}$ & W & W & $\mathrm{W}$ \\
\hline 360-degree evaluation targeted IDP & $\mathrm{S}$ & $\mathrm{S}$ & W & $\mathrm{W}$ & $\mathrm{W}$ \\
\hline Traditional leadership program & $\mathrm{S}$ & M & $\mathrm{W}$ & W & $\mathrm{W}$ \\
\hline $\begin{array}{l}\text { Half traditional leadership } \\
\text { development program } \\
\text { including the IDP }\end{array}$ & $\mathrm{S}$ & M & $\mathrm{S}$ & M & W \\
\hline $\begin{array}{l}\text { Developmental tasks with IDP aiming } \\
\text { at the feedback system based on } \\
\text { simulation }\end{array}$ & $\mathrm{S}$ & $\mathrm{S}$ & M & M & W \\
\hline Developmental tasks & M & $\mathrm{S}$ & M & $\mathrm{S}$ & $\mathrm{S}$ \\
\hline One-on-one coaching & $\mathrm{S}$ & $\mathrm{S}$ & $\mathrm{S}$ & $\mathrm{S}$ & M \\
\hline Action learning & $\mathrm{S}$ & $\mathrm{S}$ & $\mathrm{S}$ & $\mathrm{S}$ & $\mathrm{S}$ \\
\hline
\end{tabular}

Note: $\mathrm{W}=$ weak $; \mathrm{M}=$ moderate; $\mathrm{S}=$ strong; $\mathrm{IDP}=$ individual development plan. 
In the nine leadership development approaches, the validity of action learning aiming at five elements of development path is the strongest.

\subsubsection{The Role of Action Learning in Leadership Development}

Action learning is not a new talent development approach, but in recent years, more and more companies began to recognize and accept the action learning because action learning can link learning with business goals. Action learning is a result-oriented learning process, solving business problems not only has an immediate effect on the organization, but also promotes the ability of the participants. In general, in enterprise leadership development program, action learning can play the role as follows:

- Fully develop leadership potential. Action learning is all-round development of comprehensive quality and ability, including the leader's personal values, ideological and moral quality, code of conduct, self-awareness, team integration, and a variety of skills needed for leadership responsibilities.

- Improve training effect. Action learning effectively combines the leadership development and enterprise management practice. Action learning can not only raise their learning ability, thinking ability, innovation ability, but also can promote the improvement of the business.

- Improve efficiency. Action learning aims at solving real problems, thus it can arouse the enthusiasm of the participants, which makes participates learn, practice and reflect with open mind, and quickly raise their ability to find and solve the problem.

\subsubsection{Action Learning Process}

Action learning "seven steps" [7] specific operation method is as follows:

1) Obtain support.

This is the first and the most crucial step in the implementation of action learning. At the beginning of the study, it must obtain the support of top leaders. If the action learning project fails to obtain real recognition and support of top leaders, the project will not be able to implement successfully.

2) Determine the topic.

The topic is the core of action learning. Determining the topic must consider from the following two aspects: first, solve the concerned problems of the organization to achieve organizational goals and improve the organization's performance; second, promote individual learning and growth.

3) Form the group.

Action learning is a process combining problem solving and talent cultivation. Therefore, you should base on certain issues, choose the right team members, and give full consideration to team member departments, the diversity of profession, the contribution to the question.

4) Mobilize the authorization.

Mobilizing the authorization can ensure that the organization can invest a lot of resources to develop leaders. Moreover, it can make participants put wisdom and emotion to the leadership development program. Only in this way, leadership development program can obtain the real support and approval.

5) Discuss and catalyze.

This step is the main body of action learning. Team members according to certain problems, using specialized methods and tools, combined with the question inquiring method, discuss and analyze problems, propose solutions, develop a plan of action. With the intervention of the facilitator, team members hung the original hypothesis, understand and share the original mental model, which promotes the generation of join forces and the transformation from personal learning to organizational learning.

6) Perform and coach.

This is a key step different from general learning method. It is based on the action plan, promotes team to perform the scheme and plan, reflect and adjust the scheme in the process of plan implementation. The facilitators should provide timely guidance in the process, help find and solve the problem.

7) Summarize and solidify.

This step is to evaluate the problem solution or task completion. Besides, this step need conduct a comprehensive summary and evaluation of individual harvest in action learning. Through summarizing, the experience of group members can transfer to organizational experience that can be cured to organizational system and process, thus realize the overall progress of individuals and organizations. 


\section{Conclusions}

Integrated design is widely used in enterprise leadership development. The overall effect of leadership development not only relates to integrated design, but involves all aspects of the organization. Therefore, in the process of integrated design and implementation, you should pay attention to the following questions:

1) Top managers' support and participation.

Strong willingness to change and full support of top managers is critical to the success of leadership development project. If the attitude to action learning project of the decision makers is just formalist, without other necessary attention and support, the project cannot achieve the desired effect because participants may be careless.

2) Focus on the unification of personal development and organizational leadership development.

The urgent demand of leadership development derived from the demand of organizational reform in response to the rapidly changing environment. Action learning emphases on learning, reflection and practice, which can effectively combine personal development and organizational development. The key point is the choice of target problem. Therefore, in the design of action learning program, you should choose the most key and urgent problem facing organizations, and your solution should be based on the organizational conditions.

3) Find your own specific way.

Different organization or enterprise has its unique personality, and copying others' success simply does not obtain good effect. Therefore, enterprises should not only pay attention to learn basic principle, but also pay more attention to their own strategic goals and organizational culture in order to make a suitable leadership development plan.

\section{References}

[1] He, S.K. (2008) The Theory Basis and Realistic Way of Leadership Development. Talent Development, 5, 12-14.

[2] Ren, C.J. (2004) The Leadership Development of American Enterprise. The Chinese Talent, 10, 48-50.

[3] Wen, X. (2009) Benchmarking Enterprise Leadership Project Case Study. China Human Resources Development, 10, 61-64.

[4] Wen, M.W. (2008) The Content Selection of Ruanping Leadership Development Program. Journal of China Pudong Cadre Institute, 2, 86-92.

[5] Revans, R. (1982) The Origin and Growth of Action Learning. Chartwell Bratt, Bromley.

[6] Marquette, M., Leonard, H.S., Friedman, A.M., et al. (2012) Principles, Skills and Case of Action Learning. Junshuai Hao, Junyong Liu, Trans, People's University Press, Beijing.

[7] Li, X.P. (2013) The Study of Action Learning and Enterprise Leadership Development. Master Thesis, Yunnan University, Kunming, 14-16.

\section{Submit or recommend next manuscript to SCIRP and we will provide best service for you:}

Accepting pre-submission inquiries through Email, Facebook, LinkedIn, Twitter, etc.

A wide selection of journals (inclusive of 9 subjects, more than 200 journals)

Providing 24-hour high-quality service

User-friendly online submission system

Fair and swift peer-review system

Efficient typesetting and proofreading procedure

Display of the result of downloads and visits, as well as the number of cited articles

Maximum dissemination of your research work

Submit your manuscript at: http://papersubmission.scirp.org/ 